\title{
Whooping Cranes, 1958
}

\section{By F. G. Bard, Saskatchewan Museum cf Niatural History, Regina}

This year, 1958, will be the fourteenth year since the U.S. Fish and Wildlife Service and the Audubon Society began determined efforts to find the nesting grounds of the Whooping Crane. It is thirty-six years since the last whoopers' nests were found in Saskatchewan. Two nests were found in 1922 in the prairie region west of Saskatoon and north of the South Saskatchewan River, one by Neil Gilmour near Baliol on May 19 and the other, the famous "last" nest, by Fred Bradshaw at Muddy Lake on May 28. These finds were the reward of several years of checking reports of nesting cranes. The only known nests of the wild Whooping Crane in North America today are those under the watchful eyes of the Canadian Wildlife Service personnel who discovered the cranes' guarded secret in Wood Buffalo National Park in 1954.

Perhaps one of the greatest factors in the preservation of the Whooping Crane was the establishing of the Aransas National Wildlife Refuge in Texas in December 1937. Although this 47,000 acre refuge was intended primarily for waterfowl, it was known to be the wintering ground of 19 Whooping Cranes. The other 11 birds were in Louisiana and a wounded captive bird was in Nebraska.

The Louisiana flock rose to 13 in 1939 and fell rapidly as follows: 6 in 1940,6 in 1941,5 in 1942,4 in 1943,3 in 1944,2 in 1945,2 in 1946 , 1 in 1947 and 1 in 1948.

In the winter of 1940-41 the Aransas flock increased to 26 birds including 5 young of the year. The Aransas flock dropped suddenly in the fall of 1941 to 15 birds. These sudden losses gave cause for alarm and no doubt prompted the survey program that began in 1945. The publicity given the survey stressing the urgent need for protection of the cranes has accomplished a great deal in reducing losses in migration. Losses still occur and in some years are serious. The crash decline of the Louisiana flock in 1940 reduced the crane'population there to a level too ow for the cranes to stage a comeack. A similar loss occurred as suddenly in 1941 in the Aransas flock. Urgent appeals for safe passage for the birds in migration are proving very worthwhile but these alone will not bring the Whooping Crane out of the danger zone! The lack of regular production on the nesting grounds indicates a need for a research team working in that area. At the Aransas Refuge, research could determine the pressures on the wintering flock and the measures necessary for their constant protection. Weather, inadequate food, disease, shooting, land use and traffic are but a few of these pressures; and it is important to realize that conditions vary from day to day, season to season, and year to year.

This past year we saw the value of aviculture. Under the care of George Scott two captive birds in the Audubon Zoo at New Orleans produced two young, while twentyone wild birds succeeded in raising only four young. This would seem to argue in favour of a stepped-up management program. A small captive group of whoopers through management could produce more young than are lost in each decade. Further experiments in raising sandhills could be carried on to provide some of the answers to the problem of successfully establishing whoopers in new areas so as not to have "all our eggs $_{\text {; }}$ in one basket." Several plans are being considered which will help to increase the numbers of the wild flock, and only as a last resort should we allow the whooper to degenerate into a captive bird!

The world's whooper population as reported by the United States Fish and Wildlife Service for January, 1958 is 31 . Of these, five are in captivity-the two parent birds with the two successfully reared young in New Orleans, and one in San Antonio; and 26 are free-24 on the Aransas Refuge and two on nearby Matagorda Island. Twenty-one birds started the long flight to the Canadian nesting grounds last spring, and 24 returned to Aransas in the fall. Since the 24 birds included 4 young, one adult bird was obviously missing. The other loss for the year was one of those that remained on the Gulf and which died on the Aransas Refuge. 
Vol. XVI, No. 1

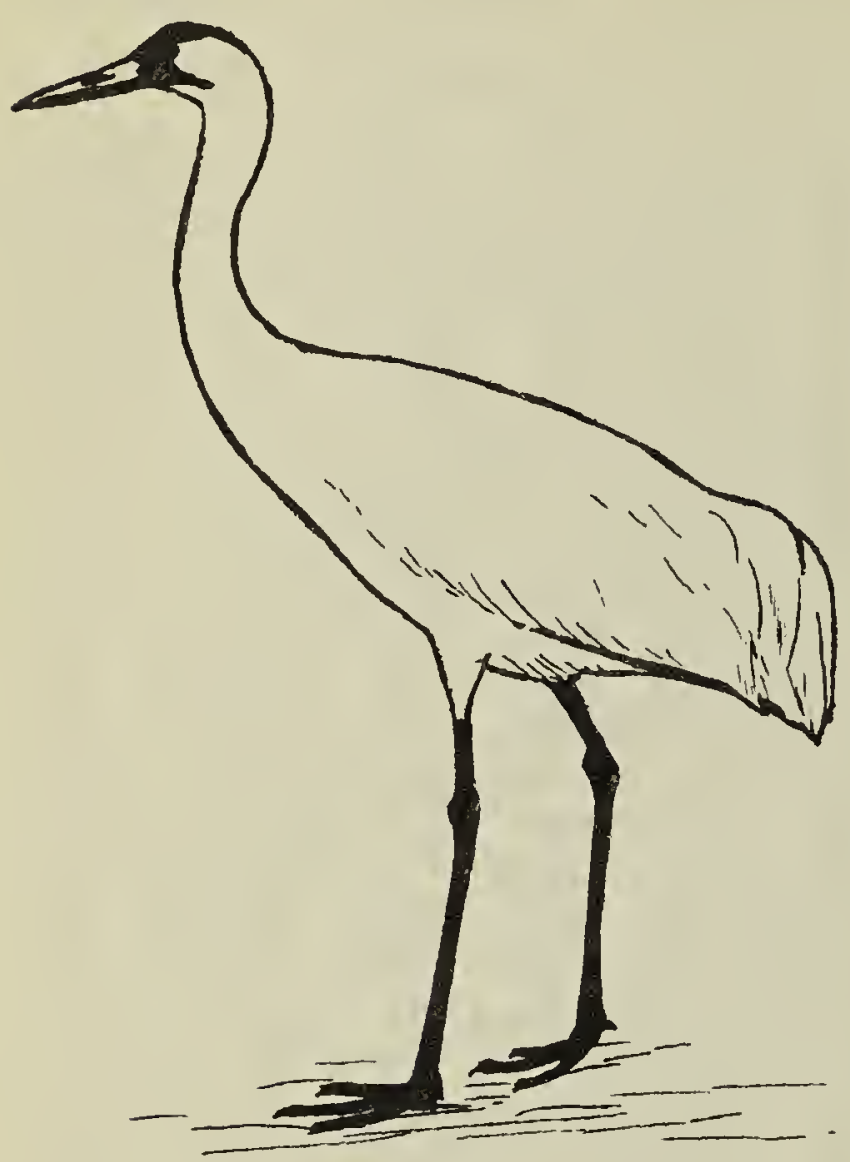

WHOOPING CRANE

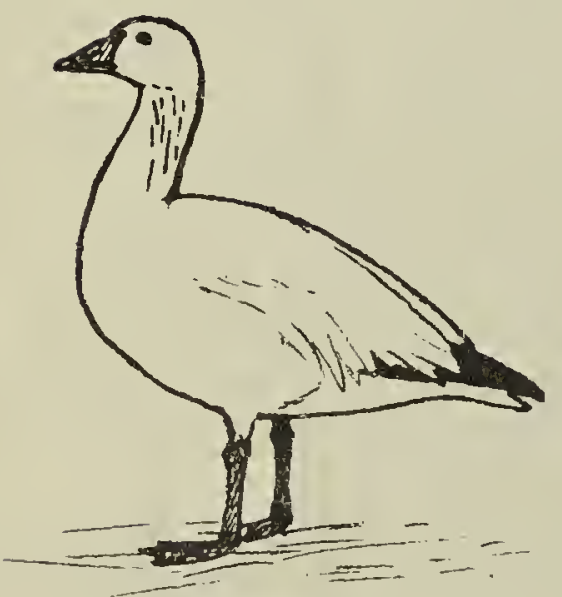

SNOW GOOSE

Why should we try to save the Whooping Crane? Whether or not the dangerously small number of Whooping Cranes is increased is perhaps not too important, but what we, as wildlife conservation agencies, are doing is important. The protection of the Whooping Crane presents one of the greatest conservation challenges of our time, and helps us to realize how important it is to

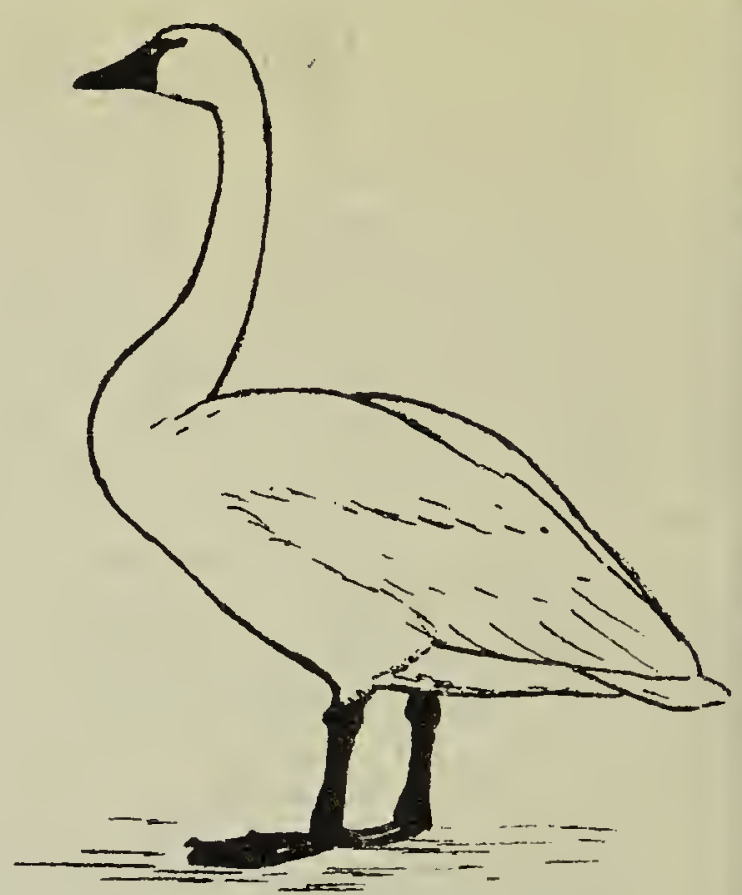

WHISTLING SWAN

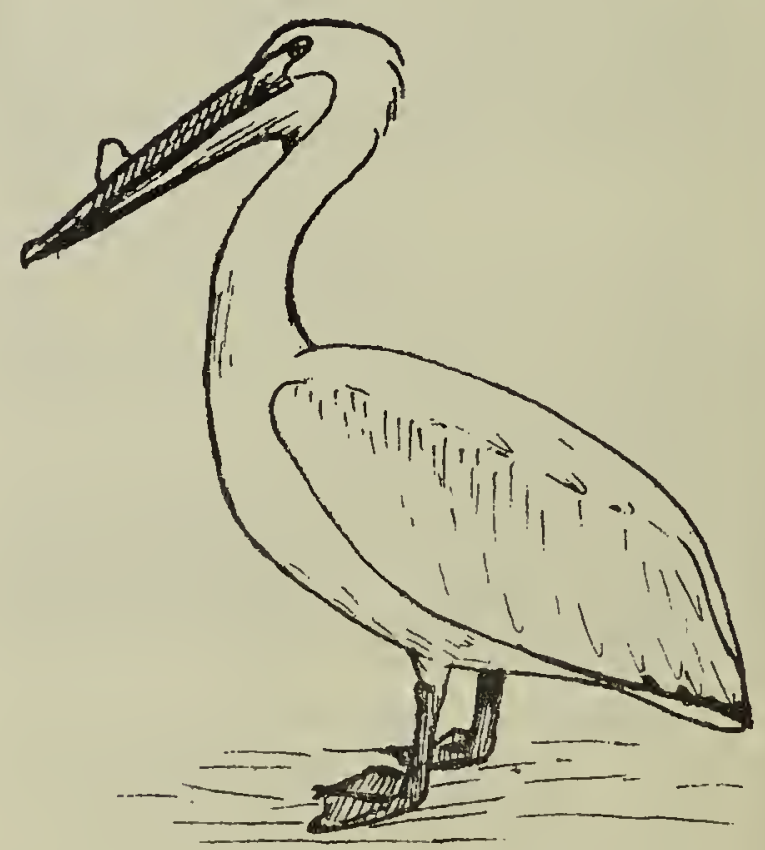

WHITE PELICAN

conserve our wildlife resources. Ir terms of economic value alone, on might point out that the cranes las year drew 33,000 tourist visitors ti the Aransas Wildlife Refuge. From every point of view, it is importan to preserve refuges where wildlife $\mathrm{i}$ protected. As we become a nation o city dwellers, we will find these rec. reational areas increasingly im portant. 


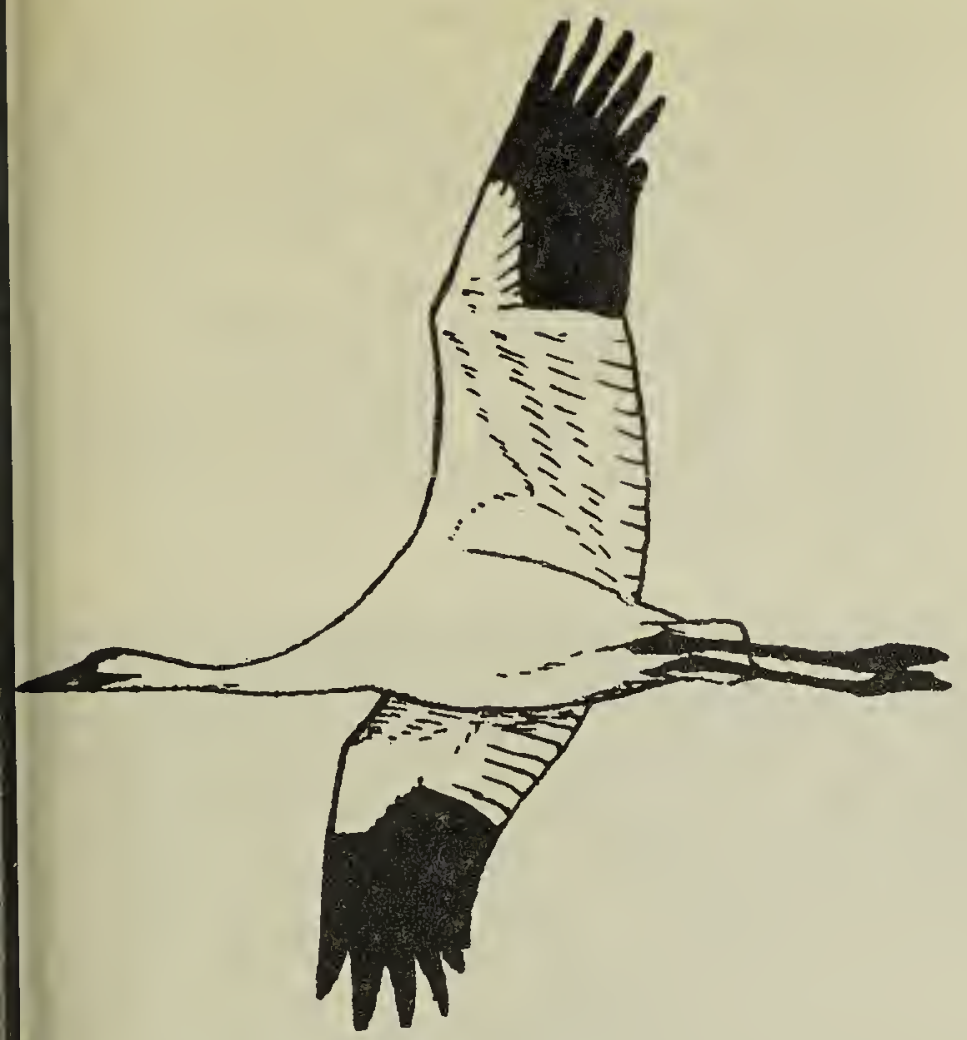

WHOOPING CRANE

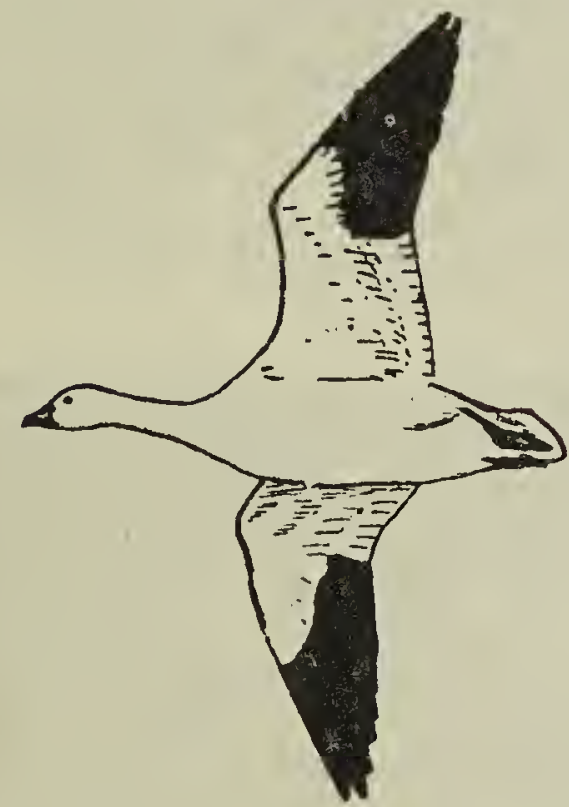

SNOW GOOSE

Until a definite policy is formulated for the management of the Whooping Crane, we must go on urging "safe passage" for them. We are glad to see the attention of the public being drawn to these birds by the recently issued American 3 cent stamp which pictures the two adult cranes' with their two young. Here in Saskatchewan we can watch for the whoopers in spring migration.

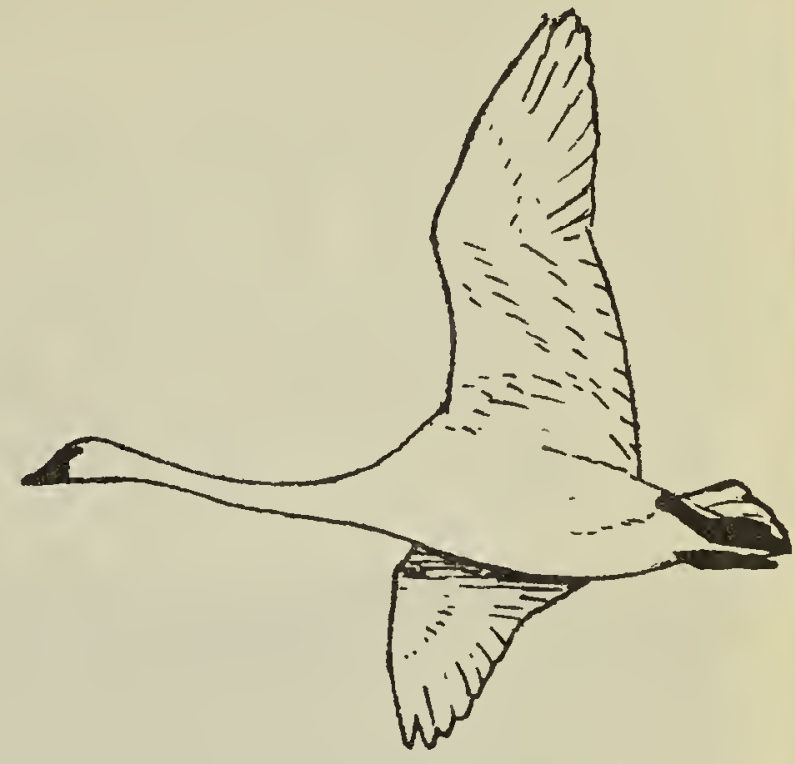

WHISTLING SWAN

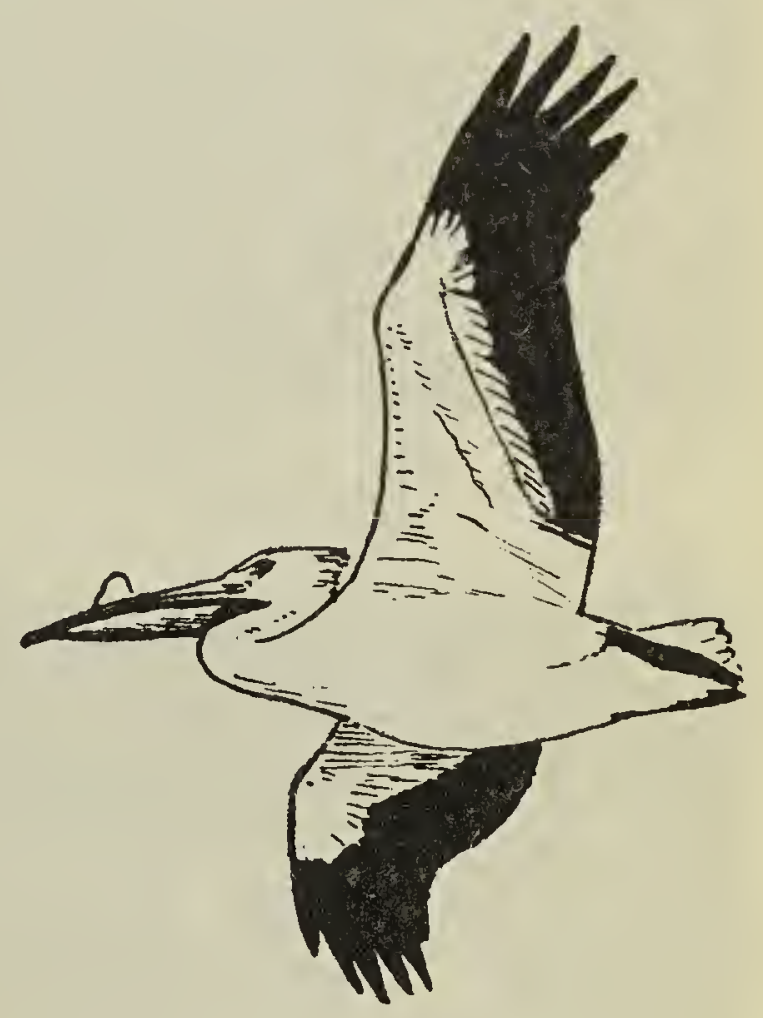

WHITE PELICAN

April 12 is the approximate date on which they leave the Aransas Refuge; and the earliest recorded arrival for Saskatchewan is April 13. Whooping Cranes may linger throughout April, but all breeding birds will have left the prairies by the end of the month. Whooping Cranes observed feeding should be reported to your nearest Conservation Officer or Wildlife Division. The cranes usually stop 
Vol. XVI, No. 1

over several days, giving ample time for field checking. In the meantime, do not disturb them!

The accompanying sketches by Fred Lahrman illustrate birds similar in appearance to the Whooping Crane. Check the legs-are they longer or shorter than the tail? Note the position of the head and neckis the head hunched on the shoulders as in herons and pelicans or is the neck straight as in swans and geese?
Finally, check the colour-is the light falling on the bird or is there backlighting? Flocks of Sandhill Cranes should be watched for whoopers. We have seen several whoopers in flocks of Sandhills.

Your interest in, and support of, the Whooping Crane survey is appreciated. From your reports we were able to field check 11 Whooping Cranes in Saskatchewan in the fall of 1957.

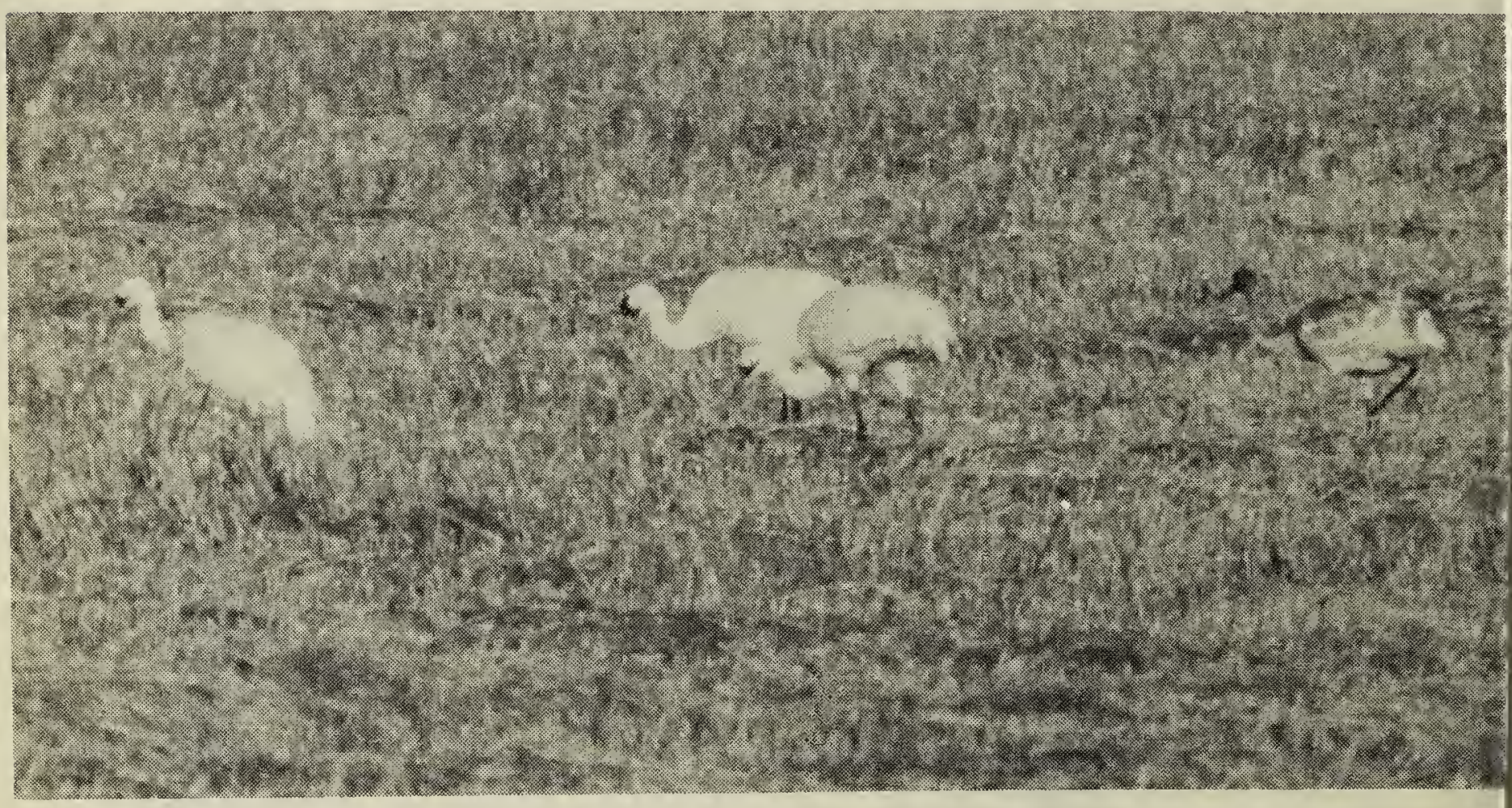

Photo by Fred Lahrman

Whooping Cranes photographed at Pierceland, Sask., October 13, 1957.

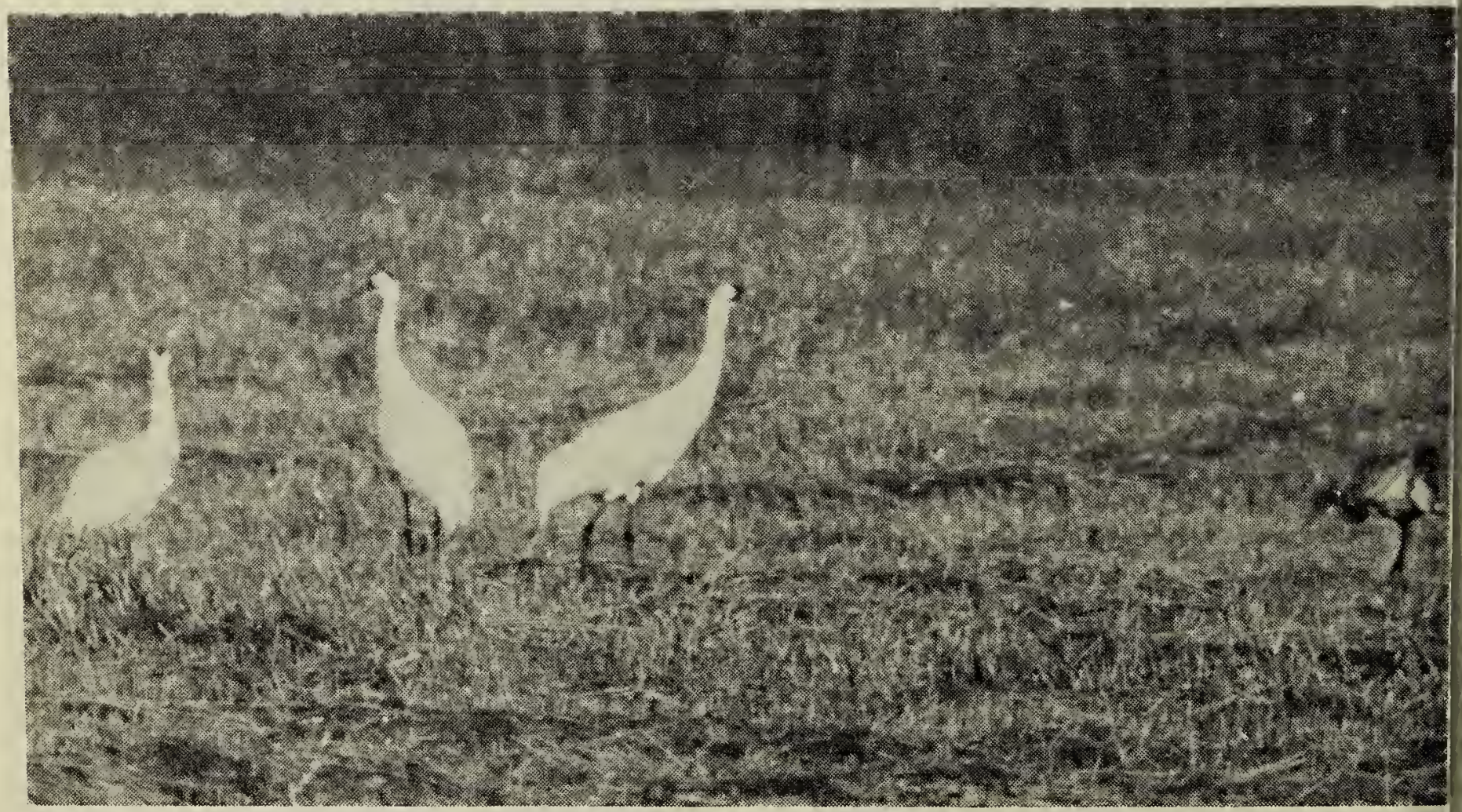

Photo by Fred Lahrman

Whooping Cranes alerted. Pierceland, Sask., October 13, 1957. 